\title{
Assessment of variations in sphenoid sinus pneumatization in Indian population: A multidetector computed tomography study
}

\author{
Shivaprakash B Hiremath, Amol A Gautam, Keerthy Sheeja, Geena Benjamin \\ Department of Radiodiagnosis, Pushpagiri Institute of Medical Sciences and Research Centre, Thiruvalla, Kerala, India
}

Correspondence: Dr. Amol A Gautam, Department of Radiodiagnosis, Pushpagiri Institute of Medical Sciences and Research Centre, Thiruvalla, Kerala - 689101, India. E-mail: gautamamol75@gmail.com

\begin{abstract}
Background and Purpose: The purpose of our study was to assess the prevalence of variations in the extent of sphenoid pneumatization in the Indian population and compare with existing literature. Materials and Methods: This retrospective study included 500 patients who underwent CT of the paranasal sinuses. The multiplanar reformations of paranasal sinus were assessed for the type of pneumatization of the sphenoid sinus and type of clival, lateral recess, lesser wing, and anterior recess extensions. Results: The conchal, presellar, incomplete sellar, and complete sellar types comprised $0 \%, 1.2 \%, 22.2 \%$, and $76.6 \%$ of patients. The extensions of pneumatization subtypes in the study population were clival in $76.6 \%$ subjects; lateral recess, lesser wing, and anterior recess in $59.7 \%, 20.4 \%$, and $20.4 \%$ of sinuses, respectively. The pure forms were seen in $25.4 \%$ and combined forms in $61 \%$ of sinuses. The presellar type $(1.2 \%)$ was less common and sellar type $(98.8 \%)$ being common in our population compared to the Caucasian and East Asian population. The sphenoid sinuses were extensively pneumatized in our population compared to the Chinese and Caucasian population, the prevalence being $76.6 \%, 68 \%$, and $44.5 \%$ for clival; $59.7 \%$, $46 \%$, and $28.3 \%$ for lateral recess; $20.4 \%, 32 \%$, and $12 \%$ for lesser wing extension, respectively. The pure forms were relatively less common and combined forms being more common compared to the Chinese and Caucasian population in our study. Conclusion: The extent of pneumatization of the sphenoid sinus has clinical and surgical implications in sellar and central skull base lesions, and variability in different populations confirms that ethnicity influences the differences in prevalence.
\end{abstract}

Keywords: Anatomic variation; cerebrospinal fluid leak; idiopathic intracranial hypertension; pituitary tumors; sphenoid sinus; transnasal endoscopic surgery

\section{Introduction}

The knowledge of anatomy and normal variants is a necessary requisite for the understanding of pathological processes in radiology. The radiological findings are

\begin{tabular}{|l|l|}
\hline \multicolumn{2}{|c|}{ Access this article online } \\
\hline Quick Response Code: & \\
\cline { 1 - 2 } & Website: \\
\hline & www.ijri.org \\
\cline { 2 - 3 } & DOI: \\
& 10.4103/ijri.IJRI_70_18 \\
\hline
\end{tabular}

complementary to the clinical features and pathology. The sphenoid bone is non-pneumatized and contains only red marrow at birth. Sphenoid pneumatization occurs in two peaks after conversion to the fatty marrow; first from birth

This is an open access journal, and articles are distributed under the terms of the Creative Commons Attribution-NonCommercial-ShareAlike 4.0 License, which allows others to remix, tweak, and build upon the work non-commercially, as long as appropriate credit is given and the new creations are licensed under the identical terms.

For reprints contact: reprints@medknow.com

Cite this article as: Hiremath SB, Gautam AA, Sheeja K, Benjamin G. Assessment of variations in sphenoid sinus pneumatization in Indian population: A multidetector computed tomography study. Indian J Radiol Imaging 2018;28:273-9. 
to four years and the second between 8 to 12 years of age. ${ }^{[1]}$ The sphenoid sinus (SS) shows signs of pneumatization as early as nine months of age. SS pneumatization shows slow development between and after peak years to reach up to the back of sella turcica by seven years and attains adult volumes by 12 to 15 years of age..$^{[2-4]}$ The SS is the most inconsistent and least accessible paranasal sinus with variations in pneumatization ranging from minimal to extensive. ${ }^{[5]}$ The SS shows variations in size, pneumatization, and pattern of septations, which lead to differences in the segmentation of SS. The pneumatization can extend into the greater wing of sphenoid, pterygoid process, clivus, and sometimes into the anterior clinoid process. ${ }^{[6,7]}$

Diverse pathologies affecting the sellar and parasellar regions and extended approaches of trans nasal endoscopic procedures to lesions affecting the floor of the middle cranial fossa, petrous apex, and pituitary lesions highlight the necessity to recognize the anatomical variations and neurovascular structures in relation to SS. ${ }^{[8,9]}$ The assessment of variations in pneumatization of SS is essential, yet there is lack of an in-depth study in the Indian population, while the prevalence has been well reported in different ethnic populations. ${ }^{[10-13]}$

The knowledge of these variants and their implications allows us to highlight their presence to the surgeon and aid in optimal patient selection, intraoperative guidance, predicting the complications of intracranial lesions, and minimize the iatrogenic complications in surgical practice. This study aims at identifying the prevalence of variations in the extent of pneumatization in the SS, comparing the results with the existing literature with an emphasis on the need to be aware of the variations in pneumatization.

\section{Materials and Methods}

\section{Study participants}

The Institute Ethics Committee approved this retrospective study. The study group included multi-detector computed tomography (CT) of paranasal sinuses of 500 consecutive patients performed between August 2016 and August 2017 after exclusion of those with facial trauma or history of surgery leading to alterations in normal anatomy, those with sinonasal tumors or younger than 16 years of age. Patients with extensive rhinosinusitis causing bony rarefaction were also excluded from the study.

\section{Image acquisition}

All the subjects underwent $\mathrm{CT}$ of the paranasal sinus with a standardized protocol. The axial CT was performed with 128 multislice scanner (Optima 660, GE Healthcare) using 120 $\mathrm{KV}$ and $110 \mathrm{mAs}$ with a $0.6-\mathrm{mm}$ slice thickness. Continuous axial sections were obtained parallel to the orbitomeatal line. The multiplanar reformatted images were analyzed on Z820 workstation.

Image analysis

Based on the images acquired by CT, they were assessed for the following variables as described: type of pneumatization of SS, type of clival, lateral, lesser wing, and anterior recess extensions of SS..$^{[10,11]}$

\section{Classification of types of pneumatization of SS}

The SS was classified into conchal, presellar, and sellar (incomplete and complete) types based on the relation to anterior and posterior walls of sella turcica on the sagittal plane [Figures 1 and 2]. The extension of pneumatization into the clivus was classified into subdorsal, dorsal, occipital, and combined (dorsal + occipital) types based on relation to the posterior wall, the floor of sella, and vidian canal [Figures 3 and 4]. The lateral extension of pneumatization was classified into the greater wing of the sphenoid, pterygoid, and full lateral (greater wing + pterygoid) extension based on the line connecting the medial aspects of foramen rotundum and vidian canal (VR Line) [Figures 5A-C and 6A]. The lesser wing extension was said to be present when there was an extension into either optic strut, lesser wing or anterior clinoid process [Figures 5D and 6A]; and the anterior recess type when the anterior wall of the sinus extended anteriorly beyond the plane of the sphenoidal crest [Figure 6B].

\section{Statistical methods}

Statistical analysis of all the data sets was performed with SPSS, Version 22 (IBM, Armonk, New York). The types of pneumatization of SS and extensions were compiled and utilized to determine the prevalence of various categories. The $P$ value of $<0.05$ indicated a significant statistical difference in Chi-square test.

\section{Results}

A total of 500 patients were assessed with CT, whose ages were ranging from 16 to 87 years with a mean of $43.13 \pm 17.39$. The study population comprised $43.4 \%$ females (217) and $56.6 \%$ male patients (283). There is no significant statistical difference in prevalence of pneumatization patterns between male and female subjects.

\section{Sphenoid sinus}

There were no patients with conchal type, $1.2 \%$ (6) of patients with presellar type, $22.2 \%$ (111) of patients with incomplete sellar type, and $76.6 \%$ (383) of patients with a complete sellar type of pneumatization [Table 1].

\section{Clival extension}

The clival extension was seen in $76.6 \%$ of the sinuses. Of the 383 sinuses with clival extension, the most 


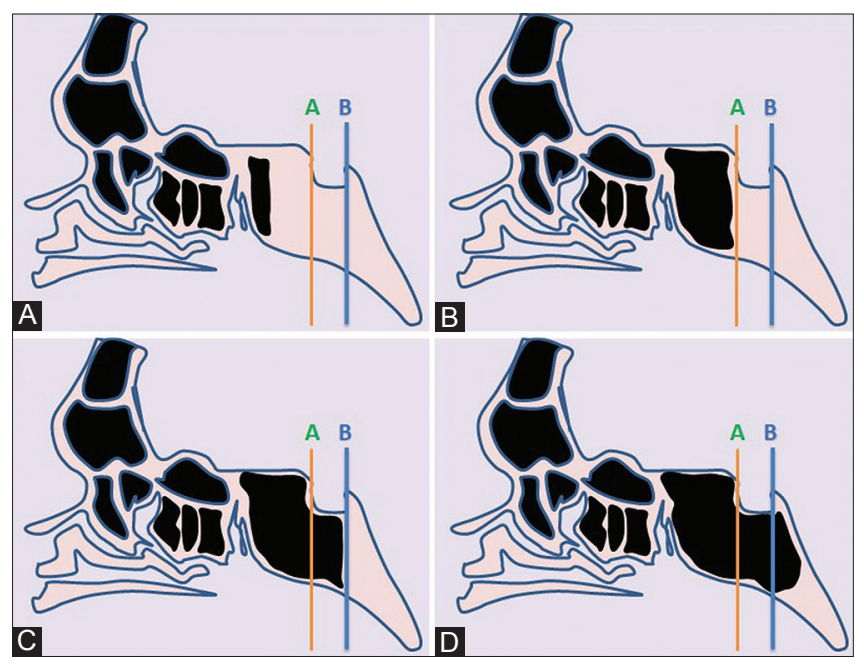

Figure 1 (A-D): Types of sphenoid pneumatization. Pictorial representation with vertical lines drawn along the anterior (orange line) and posterior walls (blue line) of the sella. (A) Conchal type; pneumatization $>10 \mathrm{~mm}$ anterior to the anterior wall of sella. (B) Presellar type; the posterior margin of pneumatization anterior to the anterior wall. (C) Incomplete sellar; the posterior margin of pneumatization beneath the sella, but anterior to the posterior wall of sella. (D) Complete sellar; the posterior margin of pneumatization, posterior to the posterior wall of sella

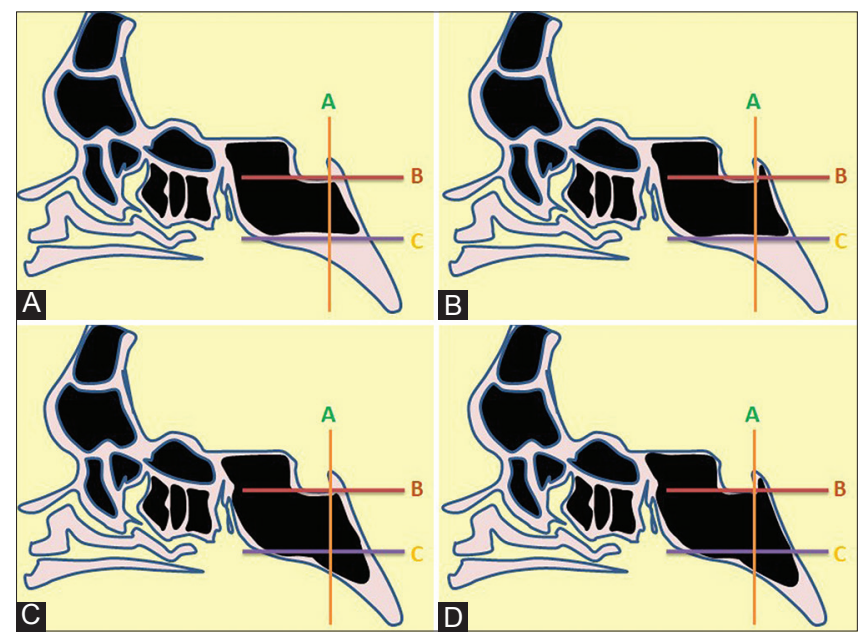

Figure $3(A-D)$ : Types of Clival extension. Pictorial representation with horizontal lines at the inferior margin of sella (brown line) and along the vidian canal (purple line), and vertical line (orange line) along the posterior wall of sella. $3 \mathrm{~A}$ - Subdorsal; Pneumatization not extending above the inferior margin of sella or below the level of the vidian canal. 3B - Dorsal; Pneumatization extending superiorly into the dorsum sella. $3 \mathrm{C}$ - Occipital; Pneumatization extending inferior to the level of the vidian canal. 3D - Combined; Dorsal + Occipital

common form was the subdorsal type (65\%, 325 patients), followed by dorsal (4\%, 20 patients), occipital (3.8\%, 19 patients), and combined type (3.8\%, 19 patients) of clival pneumatization [Tables 2 and 3].

\section{Lateral extension}

The lateral extension was found in 597 (59.7\%) of the 1000 sinus walls evaluated on CT. Among the 597 sinuses with a lateral extension, the pterygoid extension was most common,

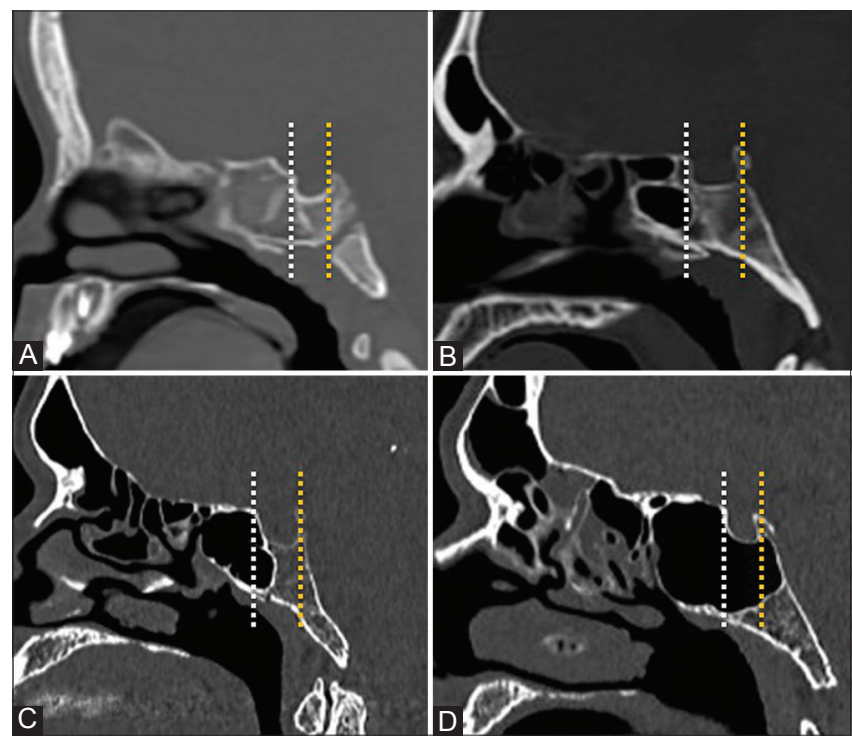

Figure $2(A-D)$ : Midsagittal images of sphenoidal sinus demonstrating conchal type (A), presellar type (B), incomplete sellar type (C), and complete sellar type (D)

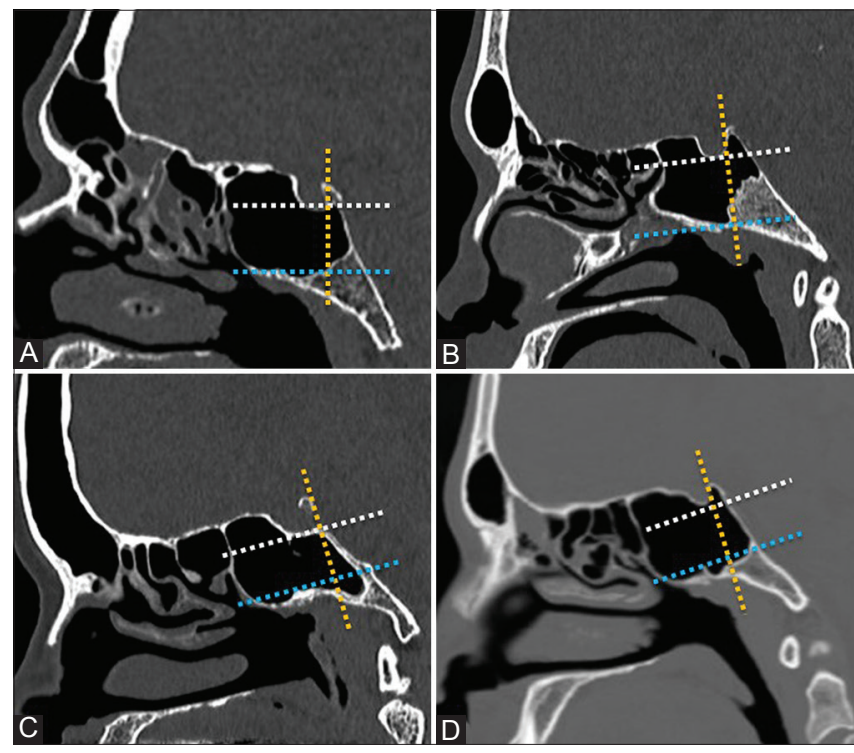

Figure 4 (A-D): Midsagittal images of sphenoidal sinus demonstrating subdorsal type (A), dorsal type (B), occipital type (C), and combined type (D)

seen in 313 (52.4\%); followed by full lateral extension seen in $273(45.7 \%)$ with greater wing of the sphenoid extension being the least, seen in $11(1.8 \%)$ [Tables 2 and 3]. There was a statistically significant difference in the lateral extension between the left and right sides, with extension commonly on the left side $(P<0.01)$.

Lesser wing extension and anterior recess

The sinus with a lesser wing pneumatization had extension into either optic strut or anterior clinoid process. The lesser wing type of pneumatization was found in 204 (20.4\%) of the sinuses examined on imaging. The optic canal was surrounded by the sphenoid air cells in lesser wing 
Hiremath, et al.: Variations in sphenoid sinus pneumatization in Indian population

type of pneumatization. The anterior recess was found in $204(20.4 \%)$ of the 1000 sinuses [Table 2].

\section{Pure and combined forms of pneumatization}

The pure subtypes of pneumatization were seen in $25.4 \%$ (254 sides) and the combined forms of pneumatization in $61 \%$ (610 sides). The common form was isolated clival extension seen in $18 \%$, followed by pure lateral in $4.3 \%$, isolated anterior recess in $2 \%$ with isolated lesser wing extension being the least common, seen in $1 \%$. The combined forms of sphenoid pneumatization are as shown in Table 4 .

\section{Discussion}

The sphenoid sinuses were classified into conchal, presellar, and sellar types initially by Hammer and Radberg, ${ }^{[14]}$ a widely accepted classification as it predicts the surgical corridor used in transsphenoidal surgeries. Guldner et al. subdivided the sellar type into incomplete and complete types based on the extension of the pneumatization beyond the posterior wall of the sella. ${ }^{[15]}$ The modifications and the traditional system focus on the posterior extent of pneumatization and the ease of accessibility of the sellar floor during endoscopic surgeries.

The study of pneumatization patterns of SS has gained added importance due to newer developments in transsphenoidal sinus surgeries and its utility in accessing the lesions involving middle cranial fossa, retroclival region, and foramen magnum. Wang et al. ${ }^{[10]}$ expanded the classification system based on anatomical and imaging studies to include the lateral and anterior extension to access possible sites in extended transsphenoidal sinus surgery. The pneumatization of SS in our study showed differences from those reported previously in literature as discussed below [Table 5].

\section{Comparison of prevalence of Sphenoid sinus pneumatization} extensions

Firstly, among the published studies from the Caucasian and East Asian populations, the overall prevalence of conchal type was 1 to $2 \%$. ${ }^{[10-12,16-20]}$ However, there were no patients with a conchal type of pneumatization in our study. There was a significant difference in the presellar type of pneumatization with overall prevalence ranging between 18.7 and $20.6 \%$ in previous literature to $1.2 \%$ in our study, highlighting that a lesser degree of pneumatization occurs commonly in the Caucasian and East Asian populations. Even though the sellar type of pneumatization was the most prevalent type in all populations, it was highest in our study $(98.8 \%)$ compared to the overall prevalence of $76.9-79.9 \%$ in the previously published literature. There was a statistically significant difference in types of SS with $P<0.01$, suggesting extensive pneumatization of SS in our population.

Secondly, the subdorsal type of clival pneumatization was the most prevalent subtype ranging from 63.2 to $84.8 \%$,
Table 1: Prevalence of types of sphenoid sinus pneumatization (500 CT scans)

\begin{tabular}{lcc}
\hline Type & Number of individuals & Percentage \\
\hline Conchal & 0 & 0 \\
Presellar & 6 & 1.2 \\
Incomplete sellar & 111 & 22.2 \\
Complete sellar & 383 & 76.6 \\
\hline
\end{tabular}

Table 2: Extensions of sphenoid pneumatization on CT ( 500 patients and 1000 sides)

\begin{tabular}{lcc}
\hline Pneumatization extension & Number of sides & Percentage \\
\hline Clival extension (Patients) & 383 & 76.6 \\
Lateral extension (Sides) & 597 & 59.7 \\
Anterior clinoid/Optic strut (Sides) & 204 & 20.4 \\
Sphenoethmoidal recess (Sides) & 204 & 20.4 \\
\hline
\end{tabular}

Table 3: Extensions of sphenoid pneumatization on CT (500 patients and 1000 sides)

\begin{tabular}{lcc}
\hline Pneumatization extension & Number of sinuses & Percentage \\
\hline Clival extension (383 patients) & & \\
Subdorsal & $325 / 383$ & 84.8 \\
Dorsal & $20 / 383$ & 5.2 \\
Occipital & $19 / 383$ & 5 \\
Combined (Dorsal + Occipital) & $19 / 383$ & 5 \\
Lateral extension (597 sinus) & & \\
Pterygoid & $313 / 597$ & 52.4 \\
Greater wing & $11 / 597$ & 1.8 \\
Full lateral & $273 / 597$ & 45.7 \\
\hline
\end{tabular}

Table 4: Types of combined sphenoid sinus based on computed tomography

\begin{tabular}{lcc}
\hline Combined type (610 sides) & $\begin{array}{c}\text { Number of } \\
\text { individuals }\end{array}$ & Percentage \\
\hline Clival + Lateral & 286 & 46.8 \\
Clival + Lateral + Lesser Wing & 114 & 18.7 \\
Clival + Lateral + Anterior & 90 & 14.7 \\
Clival + Lateral + Lesser Wing + Anterior & 41 & 6.7 \\
Clival + Anterior & 34 & 5.6 \\
Clival + Lesser Wing & 13 & 2.1 \\
Lateral + Lesser Wing & 13 & 2.1 \\
Clival + Lesser Wing + Anterior & 7 & 1.1 \\
Lateral + Anterior & 6 & 1 \\
Lateral + Lesser Wing + Anterior & 4 & 0.6 \\
Lateral + Anterior & 2 & 0.3 \\
Lesser Wing + Anterior & 2 & 0.3 \\
\hline
\end{tabular}

being highest in our study. There was a difference in the prevalence of other subtypes with the least common subtype being occipital in the study by Wang et al. (Caucasian) and complete in the study by Lu et al. (Chinese). Both occipital and complete types were less common in our study. There was a statistically significant difference in prevalence of subtypes of clival pneumatization with $P<0.01$. The 
Table 5: Comparison of prevalence of sphenoid sinus types and clival pneumatization

\begin{tabular}{|c|c|c|c|c|c|}
\hline Sphenoid sinus types & Conchal & Presellar & Sellar & Postsellar & $P$ \\
\hline \multicolumn{6}{|l|}{ Caucasian } \\
\hline Hamid et al. 2008 & 6 & 62 & 162 & 66 & $<0.001$ \\
\hline Wang et al. 2010 & 0 & 2 & 98 & & \\
\hline Lupascu et al. 2014 & 6 & 56 & 138 & & \\
\hline Sevinc et al. 2014 & 3 & 102 & 511 & & \\
\hline Vaezi et al. 2014 & 3 & 24 & 75 & & \\
\hline Total & $18(1.3 \%)$ & $246(18.7 \%)$ & $1050(79.9 \%)$ & & \\
\hline \multicolumn{6}{|l|}{ East Asian } \\
\hline Li et al. 2010 & 5 & 80 & 175 & & \\
\hline Lu et al. 2011 & 12 & 57 & 131 & & \\
\hline Anusha et al. 2015 & 1 & 20 & 279 & & \\
\hline Total & $18(2.3 \%)$ & $157(20.6 \%)$ & $585(76.9 \%)$ & & \\
\hline \multicolumn{6}{|l|}{ Indian } \\
\hline Our study & 0 & 6 & 111 & 383 & \\
\hline Total & $0(0 \%)$ & $6(1.2 \%)$ & $494(98.8 \%)$ & & \\
\hline Clival pneumatization & Subdorsal & Dorsal & Occipital & Complete & \\
\hline \multicolumn{6}{|l|}{ Caucasian } \\
\hline Wang et al. 2010 & $43(63.2 \%)$ & $16(23.5 \%)$ & $1(1.5 \%)$ & $8(11.8 \%)$ & $<0.001$ \\
\hline \multicolumn{6}{|l|}{ Chinese } \\
\hline Lu et al. 2011 & $64(72 \%)$ & $11(12.3 \%)$ & $13(14.6 \%)$ & $1(1.1 \%)$ & \\
\hline \multicolumn{6}{|l|}{ Indian } \\
\hline Our study & $325(84.8 \%)$ & $20(5.2 \%)$ & $19(5 \%)$ & $19(5 \%)$ & \\
\hline
\end{tabular}

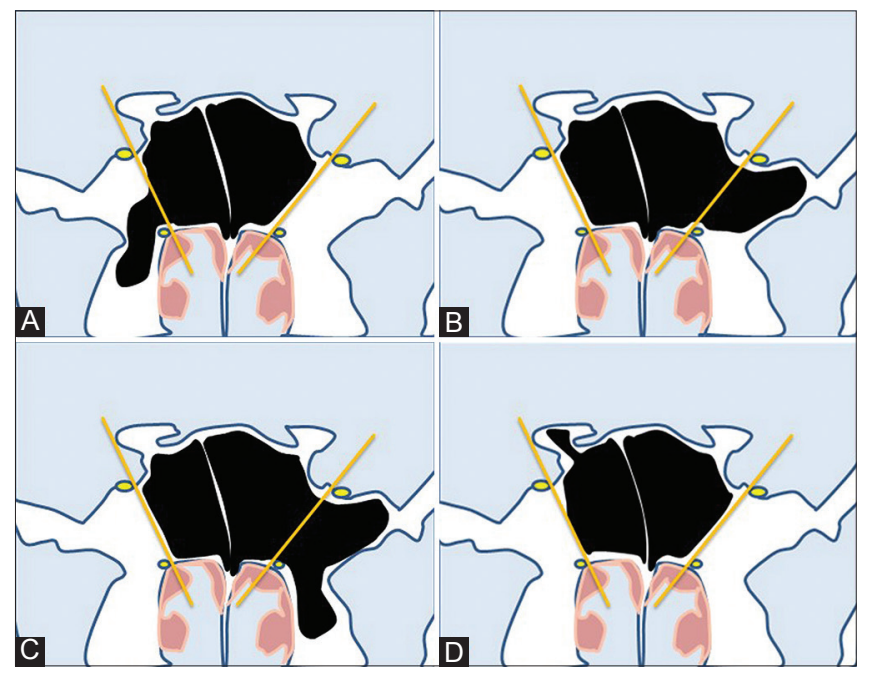

Figure $\mathbf{5}$ (A-D): Types of lateral and lesser wing extension. Pictorial representation with a line drawn along the medial margins of foramen rotundum and vidian canal (orange line) on both sides. (A) Pterygoid; pneumatization extending inferior to the vidian canal on the right side into the pterygoid process. (B) Greater wing of sphenoid; pneumatization extending laterally into greater wing of sphenoid on the left side, beyond the foramen rotundum. (C) Full lateral; pterygoid + lateral on left side. (D) Lesser wing; pneumatization extending into the anterior clinoid process on the right side

lateral extension was seen in $28.3 \%$ in the Chinese, $46 \%$ in the Caucasian, and $59.7 \%$ in our study. The bony pneumatization also differed in lesser wing of sphenoid extension (12\% in Chinese, 32\% in Caucasian, and $20.4 \%$ in our study).

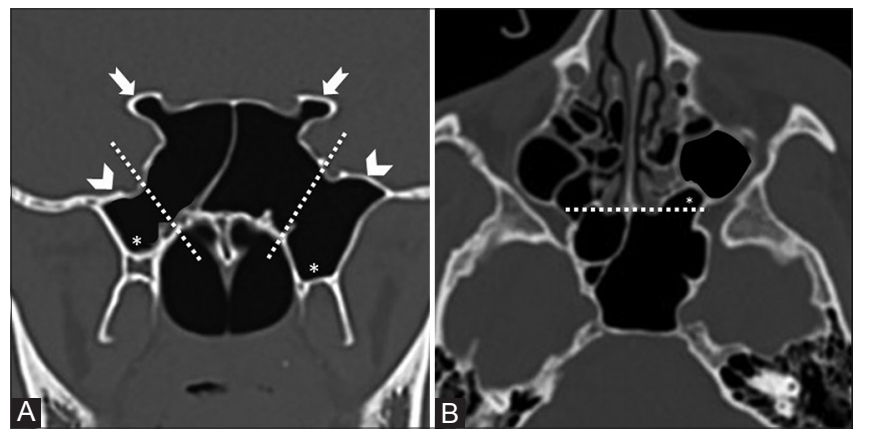

Figure 6 (A and B): Lateral, lesser wing and anterior extensions. (A) The coronal section of sphenoid sinus showing greater wing extension (arrow head), pterygoid extension (asterisk) and lesser wing extension (notched arrow). (B) The extension of pneumatization anterior to sphenoidal crest (white line), i.e., sphenoethmoidal recess on the left side (asterisk)

Thirdly, there were differences in pure and combined forms of sphenoid pneumatization as well. The difference in the prevalence of pure clival forms $(21.4 \%$ in Chinese, $11.2 \%$ in Caucasian, and $18.1 \%$ in our study); pure lateral and lesser wing extensions $(11.4 \%$ and $0.8 \%$ in Chinese with similar prevalence rates in Caucasian, $4.3 \%$ and $1 \%$ in our study). By contrast, the combined forms of SS were more frequent in our study (61\%), compared to $59.2 \%$ in Caucasian and $48.1 \%$ in Chinese population. This epidemiological study of pneumatization patterns of SS highlights its variability in different populations and confirms with the existing literature that ethnicity influences the differences in prevalence. ${ }^{[21]}$ 


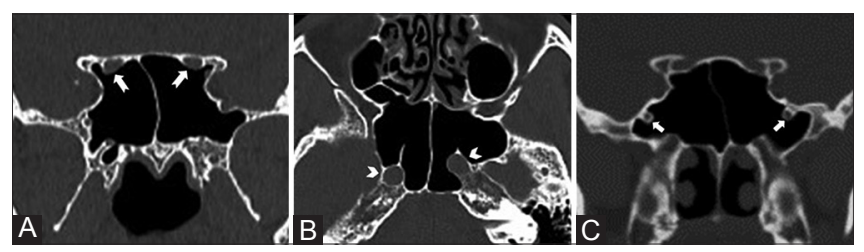

Figure 7 (A-C): Intrasphenoid course of optic nerve, internal carotid artery, and maxillary nerve. (A) Coronal CT showing clinoid extension of pneumatization with optic nerve coursing through sphenoid sinus. (B) Axial CT showing intrasphenoid extension of internal carotid artery. (C) Coronal CT showing intrasphenoid extension of maxillary nerve

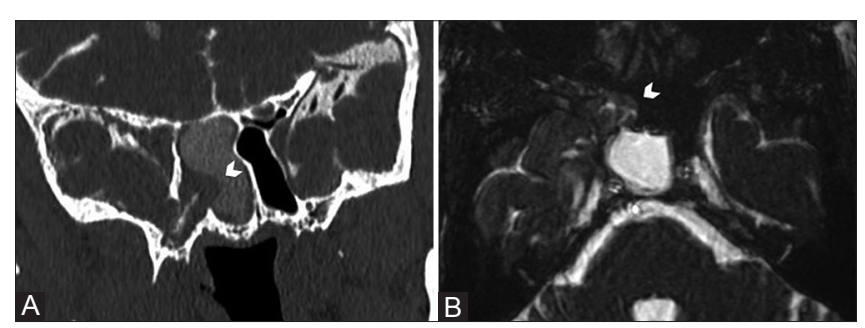

Figure 9 (A and B): Coronal CT cisternography (A) and axial FIESTA $(B)$ in a patient with idiopathic intracranial hypertension showing bony erosion involving lateral wall of sphenoid sinus with herniation of medial temporal lobe suggesting sphenoidal encephalocele (arrow head)

Clinical and surgical implications of sphenoid sinus pneumatization

The arrested and under pneumatization of SS is uncommon in our population. Cystic fibrosis and sickle cell disease are commonly associated with arrested pneumatization and underdeveloped paranasal sinuses than in the general population. The presence of such variants should highlight the likely etiology in appropriate clinical settings. ${ }^{[22,23]}$ Nonpneumatized and conchal pneumatization are less favorable for a transsphenoidal approach to sellar and parasellar lesions. These subtypes require drilling and removal of thick cancellous bone, resulting in an increased operative time. However, access to sella is safe with the availability of intraoperative navigation after confirmation of surgical landmarks in these subtypes. ${ }^{[24,25]}$

The hyperpneumatization of SS not only allows extended approaches of transsphenoidal surgeries but also increases the likelihood of collision between operative instruments and chances of iatrogenic injuries. The posterior extension of aeration into the clivus, dorsum sella, and anterior extension into planum sphenoidale may result in an inadvertent damage to the bony walls of the sphenoid sinus, resulting in cerebrospinal fluid (CSF) leaks. ${ }^{[16]}$ The bony dehiscence and protrusion of the adjacent neurovascular structures into the SS increase in proportion to the pneumatization. ${ }^{[26,27]}$ The lesser wing extension leads to the protrusion and thinning of bony wall of the optic nerve and internal carotid artery, thereby increasing susceptibility to injury during endoscopic surgeries [Figure 7A and B). ${ }^{[27]}$ The extension into the clinoid process needs a special mention in presurgical evaluation of sellar-suprasellar masses and periclinoid aneurysms to avoid post-surgical CSF
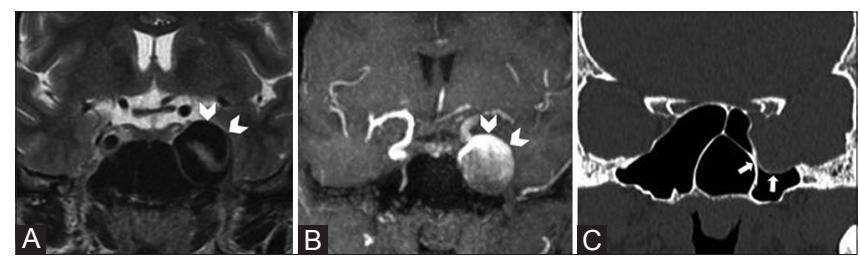

Figure 8 (A-C): Coronal T2W (A), TOF angiography (B), and CT of sphenoid sinus in bone window (C) showing left internal carotid artery aneurysm involving cavernous segment (arrow head) causing bony remodeling of lateral sphenoid wall (arrows)

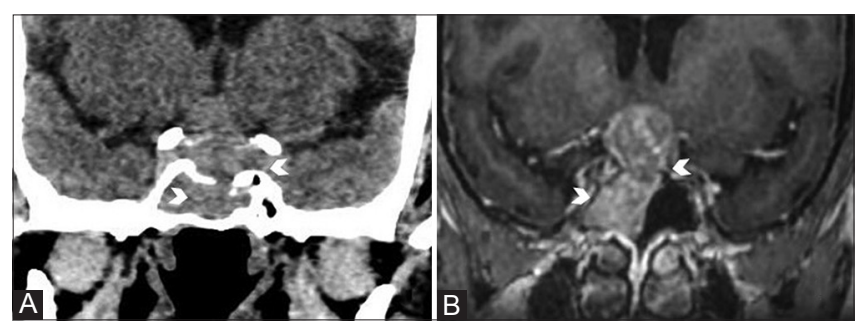

Figure 10 ( $A$ and $B$ ): Coronal $C T$ in brain window $(A)$ and post-contrast T1W (B) images showing erosion of sellar floor and intrasphenoid extension of pituitary macroadenoma

leaks [Figure 8]. ${ }^{[28]}$ The lateral extension into the pterygoid process and greater wing of sphenoid also render maxillary nerve, vidian nerve, and carotid artery susceptible to iatrogenic injury [Figure $7 C$ ]. ${ }^{[29,30]}$ Such individuals can also present with vidian and or maxillary neuralgia as a complication of inflammatory sinus disease. Extensive pneumatization of the SS and lateral recess increases susceptibility to bony erosion and spontaneous CSF leaks in idiopathic intracranial hypertension and extension of sellar and parasellar lesions into SS [Figure 9 and 10]. ${ }^{[31,32]}$ The radiology template that can be included in the paranasal sinus CT reporting for assessment of sphenoid sinus pneumatization is shown in Supplementary Table 1.

Although we have extensively studied on SS pneumatization in the Indian population, our study has a few limitations: First, the inclusion of relatively asymptomatic patients in this retrospective study. Although few studies describe pneumatization in pathological conditions, we require further studies to ascertain the role of pneumatization in chronic sinusitis as well as post-operative outcomes and prognosis in sellar pathologies. ${ }^{[3,34]}$ Second, the correlation between the extent of pneumatization of the SS, dehiscence, and protrusion of adjacent neurovascular structures into SS were not assessed in this study. Further studies concerning this topic are needed to ascertain the association.

\section{Conclusion}

This study describes extensive clival and lateral extension of sphenoid sinus pneumatization with an increased prevalence of combined forms in the Indian population compared to other ethnic population. Although extensive pneumatization of sphenoid sinus facilitates extended 
approaches of transsphenoidal endoscopic surgeries, it poses an increased risk of iatrogenic complications such as neurovascular injuries and CSF leaks, the higher propensity of bony erosion, and sinus extension of sellar and parasellar mass lesions in our population. Radiologists need to be aware of these variations and include them in routine reporting templates.

\section{Financial support and sponsorship}

None.

\section{Conflicts of interest}

There are no conflicts of interest.

\section{References}

1. Wolf G, Anderhuber W, Kuhn F. Development of the paranasal sinuses in children: Implications for paranasal sinus surgery. Ann Otol Rhinol Laryngol 1993;102:705-11.

2. Adibelli $\mathrm{ZH}$, Songu M, Adibelli H. Paranasal sinus development in children: A magnetic resonance imaging analysis. Am J Rhinol Allergy 2011;25:30-5.

3. Antoniades K, Vahtsevanos K, Psimopoulou M, Karakasis D. Agenesis of sphenoid sinus: Case report. ORL J Otorhinolaryngol Relat Spec 1996;58:347-9.

4. Schatz CJ, Becker TS. Normal CT anatomy of the paranasal sinuses. Radiol Clin North Am 1984;22:107-18.

5. Hewaidi GH, Omami GM. Anatomical variation of sphenoid sinus and related structures in Libyan population: CT scan study. Libyan J Med 2008;3:128-33.

6. Teatini G, Simonetti G, Salvolini U, Masala W, Meloni F, Rovasio S, et al. Computed tomography of the ethmoid labyrinth and adjacent structures. Ann Otol Rhinol Laryngol 1987;96:239-50.

7. Yune H, Holden R, Smith J. Normal variations and lesions of the sphenoid sinus. Am J Roentgenol 1975;124:129-38.

8. Ceylan S, Koc K, Anik I. Extended endoscopic approaches for midline skull-base lesions. Neurosurg Rev 2009;32:309-19.

9. Kim EH, Ahn JY, Kim SH. Technique and outcome of endoscopy-assisted microscopic extended transsphenoidal surgery for suprasellar craniopharyngiomas. J Neurosurg 2011;114:1338-49.

10. Wang J, Bidari S, Inoue K, Yang H, Rhoton A Jr. Extensions of the sphenoid sinus: A new classification. Neurosurgery 2010;66:797-816

11. Lu Y, Qi S, Shi J, Zhang X, Wu K. Pneumatization of the sphenoid sinus in Chinese: The differences from Caucasian and its application in the extended transsphenoidal approach. J Anat 2011;219:132-42.

12. Anusha B, Baharudin A, Philip R, Harvinder S, Shaffie BM, Ramiza RR. Anatomical variants of surgically important landmarks in the sphenoid sinus: A radiologic study in Southeast Asian patients. Surg Radiol Anat 2015;37:1183-90.

13. Gibelli D, Cellina M, Gibelli S, Oliva AG, Termine G, Sforza C. Anatomical variants of sphenoid sinuses pneumatisation: A CT scan study on a Northern Italian population. Radiol Med 2017;122:575-80.

14. Hammer G, Radberg C. The sphenoidal sinus. An anatomical and roentgenologic study with reference to transsphenoid hypophysectomy. Acta Radiol 1962;56:401-22.

15. Güldner C, Pistorius SM, Diogo I, Bien S, Sesterhenn A, Werner JA. Analysis of pneumatization and neurovascular structures of the sphenoid sinus using cone-beam tomography (CBT). Acta Radiol

\section{2;53:214-9.}

16. Hamid O, El Fiky L, Hassan O, Kotb A, El Fiky S. Anatomic variations of the sphenoid sinus and their impact on trans-sphenoid pituitary surgery. Skull Base 2008;18:9-15.

17. Lupascu M, Comsa Gh. I, Zainea V. Anatomical variations of the sphenoid sinus-a study of 200 cases. ARS Medica Tomitana 2014;2:57-62.

18. Sevinc O Is M, Barut C, Erdogan A. Anatomic Variations of Sphenoid Sinus Pneumatization in a Sample of Turkish Population: MRI Study. Int J Morphol 2014;32:1140-3.

19. Vaezi A, Cardenas E, Pinheiro-Neto C, Paluzzi A, Branstetter BF $4^{\text {th }}$, Gardner PA, et al. Classification of Sphenoid Sinus Pneumatization: Relevance for Endoscopic Skull Base Surgery. Laryngoscope 2015;125:577-81.

20. Li SL, Wang ZC, Xian JF. Study of variations in adult sphenoid sinus by multislice spiral computed tomography. Zhonghua Yi Xue Za Zhi. 2010; 90:2172-6.

21. Anusha B, Baharudin A, Philip R, Harvinder S, Shaffie BM. Anatomical variations of the sphenoid sinus and its adjacent structures: A review of existing literature. Surg Radiol Anat 2014;36:419-27.

22. Eggesbø HB, Søvik S, Dølvik S, Eiklid K, Kolmannskog F. Ct Characterization of Developmental Variations of the Paranasal Sinuses in Cystic Fibrosis, Acta Radiol 2001;42:482-93.

23. Prabhu AV, Branstetter IV BF. The CT prevalence of arrested pneumatization of the sphenoid sinus in patients with sickle cell disease. AJNR Am J Neuroradiol. 2016;37:1916-9.

24. Zada G, Agarwalla PK, Mukundan S, Dunn I, Golby AJ, Laws ER Jr. The neurosurgical anatomy of the sphenoid sinus and sellar floor in endoscopic transsphenoidal surgery. J Neurosurg 2011;114:1319-30.

25. Nomikos P, Fahlbusch R, Buchfelder M. Recent developments in trans-sphenoidal surgery of pituitary tumors. Hormones 2004;3:85-91.

26. Cho JH, Kim JK, Lee JG, Yoon JH. Sphenoid sinus pneumatization and its relation to bulging of surrounding neurovascular structures. Ann Otol Rhinol Laryngol 2010;119:646-50.

27. Güldner C, Pistorius SM, Diogo I, Bien S, Sesterhenn A, Werner JA. Analysis of pneumatization and neurovascular structures of the sphenoid sinus using cone-beam tomography (CBT) Acta Radiol 2012;53:214-9.

28. Spektor S, Dotan S, Mizrahi CJ. Safety of drilling for clinoidectomy and optic canal unroofing in anterior skull base surgery. Acta Neurochir 2013;155:1017-24.

29. Unal B, Bademci G, Bilgili YK, Batay F, Avci E. Risky anatomic variations of sphenoid sinus for surgery. Surg Radiol Anat 2006;28:195-201.

30. Citardi MJ, Gallivant RP, Batra PS, Maurer CR Jr, Rohlfing T, Roh HJ, et al. Quantitative computer-aided computed tomography analysis of sphenoid sinus anatomical relationships. Am J Rhinol 2004;18:173-8.

31. Schlosser RJ, Bolger WE. Significance of empty sella in cerebrospinal fluid leaks. Otolaryngol Head Neck Surg 2003; 128:32-8.

32. El-Tarabishi MN, Fawaz SA, Sabri SM, El-Sharnobi MM, Sweed A. A modification of endoscopic endonasal approach for management of encephaloceles in sphenoid sinus lateral recess. Eur Arch Otorhinolaryngol 2016;273:4305-14.

33. Kazkayasi M, Karadeniz Y, Arikan OK. Anatomic variations of the sphenoid sinus on computed tomography. Rhinology 2005;43:109-14.

34. Kuan EC, Yoo F, Kim W, Badran KW, Heineman TE, Sepahdari AR. Anatomic Variations in Pituitary Endocrinopathies: Implications for the Surgical Corridor. J Neurol Surg B Skull Base 2017;78:105-11. 